\title{
Science, Reason, and Robots
}

\author{
by Philip Yaffe
}

\section{Editor's Introduction}

Science depends on logical reasoning. However, the conclusions one comes to intimately depend on the explicit, or more often implicit, assumptions on which the reasoning is based. Here is an example of how logical reasoning based on different assumptions can lead to diametrically opposite conclusions. 


\title{
Science, Reason, and Robots
}

\author{
by Philip Yaffe
}

It is often said what distinguishes true science fiction from space soap operas is its ability to examine fundamental questions of ethics, philosophy, and sociology in situations so remote from contemporary life that they can be considered with greater acuity and less emotion. I was recently reminded of this when I inadvertently reread a short story by Isaac Asimov.

Anyone who knows anything about science fiction, and indeed science itself, is almost certainly familiar with this name. With more than 500 books to his name as both an author and editor, Asimov (19201992) was a professor of biochemistry at Boston University. He is universally recognized as one of the founding fathers of modern science fiction. He was also the nonpareil author of bestselling works on popular science, mathematics, religion, Shakespeare, and a wide variety of other topics.

The name of this specific short story is simply "Reason." It recounts the intellectual confrontation between two astronauts, who are manning a space station to channel solar energy back to an overcrowded Earth, and one of their robot workers. Donavan and Powell recently assembled the robot from components sent from Earth. Compared to the others working on the station, this is an advanced robot. To the astronauts' surprise, Cutie (QT-1) has the intellectual capacity to speculate on its own existence and on that of its human "masters." Based on pure reason, the robot comes to the conclusion that the two humans cannot possibly be his masters. The following discourse between Cutie and the astronauts has been abbreviated for the purposes of this essay, but nothing of importance has been left out [1].

Cutie: "I have spent the last two days in concentrated introspection and the results have been most interesting. I began it at the one sure assumption that I felt permitted to make. I, myself, exist, because I think. And the question that immediately arose was: Just what is the cause of my existence?"

Powell: "You're being foolish. I told you already that we made you. And if you don't believe us, we'll gladly take you apart."

Cutie: "I accept nothing on authority. A hypothesis must be backed by reason or else it is worthless-and it goes against all the dictates of logic to suppose that you made me."

"Look at you. I say this in no spirit of contempt, but look at you! The material you are made of is soft and flabby, lacking endurance and strength, depending for energy on the inefficient oxidation of organic material-like that! (Cutie points a disapproving finger at Donavon's unfinished sandwich.) Periodically you pass into a coma and the least variation of temperature, pressure, humidity, or radiation intensity impairs your efficiency." 
"I, on the other hand, am a finished product. I absorb electrical energy directly and use it with an almost 100 percent efficiency. I am composed of strong metal, am continuously conscious, and can stand extremes. These are facts which, with the self-evident proposition that no being can create another being superior to itself, smash your silly hypothesis to nothing."

You may already have noticed reference to two important philosophical precepts.

- René Descartes' famous: "I think; therefore, I am" (Cogito ergo sum).

- No being can create another being superior to itself, which is a fundamental creationist argument against evolution.

The discussion continues. Cutie extends his logic to decide that space, stars, and the planets beyond the space station do not really exist. He invents his own religion. Since everything on the station is dedicated to keeping the apparatus that is collecting energy from the Sun in good working order, this must be the Master and Cutie is his prophet. Donavan and Powell are simply earlier creations of the Master, which have now been superseded by robots. Thus, their commands can be ignored.

All attempts by the two astronauts to dissuade Cutie fail. I will not give away the end of the story, because in typical Asimov fashion it is not what you would expect. You can read the full story, along with several other Asimov gems, at the Higher Intellect database.

The important thing, however, is not who won or who lost, or if either did, but the reasoning process.

Both reasoning processes are perfectly correct because they are exactly the same. But how they are applied differs in two key respects.

\section{Weasel Words}

Weasel words are words that seem to say something important, but on inspection actually say little or nothing at all.

Cutie considers himself and the other robots to be superior to the two astronauts for the reasons enumerated above. Donavan and Powell of course disagree that having a metal body instead of flesh and blood, using energy directly rather than ingesting and digesting food, not requiring sleep, etc. necessarily make robots superior. The word "superior" therefore means one thing to Cutie and something quite different to the astronauts.

\section{Hidden Assumptions}

Both Cutie and the astronauts argue starting from assumptions (postulates) because they have no choice.

It is not possible to know everything about everything in the universe, so we must all make certain assumptions. To the scientific mind, assumptions are always subject to change based on new information. To the non-scientific mind, assumptions are the bedrock of the universe, either not to be tested or to be blindly clung to even when new information suggests they may be wrong. 
Cutie is absolutely convinced Donavan and Powell could not have made him because the idea does not logically follow from his assumptions. Moreover, he is not willing to test his conviction. When Powell offers to prove they had indeed made him by taking him apart, Cutie simply dismisses the idea.

Asimov's story has had major impact. Just plug "Isaac Asimov" + "Reason" into any Internet search engine and you will find almost endless references. The same theme was masterly explored by $\mathrm{H}$. G. Wells (1866-1946) many years before Asimov in his 1904 classic short story "The Country of the Blind" [2].

While vacationing in Ecuador, a mountain climber named Nunez slips and falls down the far side of the mountain into a valley cut off from the rest of the world by steep precipices. Many years earlier, a strange disease had struck the villagers living there, rendering all newborns blind. Inevitably, the entire population had become blind.

When Nunez realizes he is the only sighted person in the valley, he remembers the adage "In the country of the blind, the one-eyed man is king." He therefore thinks that he can teach and rule these people. But it doesn't quite turn out that way.

Over the generations, the villagers had fully adapted to life without sight. Having no concept of vision, they do not understand Nunez's attempts to explain it to them. Instead, they believe him to be delusional. When the villagers discover the bumps of his eyeballs (their own eyeballs had atrophied generations earlier), they consider them to be brain tumors, causing his delusion. They want to cut them out in order to return him to normality.

Does the moral of these two stories and many others like them mean that assumptions are dangerous and should be eradicated?

Not at all. We couldn't live without assumptions. For example, we couldn't move if we didn't assume that when we take a step, the floor will support our weight rather than our foot crashing straight through it. Admittedly, this assumption is based on years and years of experience. However, as babies crawling around on all fours, we made this and other such assumptions without ever thinking about them.

What these stories demonstrate is every assumption contains the possibility of being flawed. We should always be ready to deal with any flaw when it is revealed to us, rather than intransigently dismissing it simply because it has never before been noticed.

Even the greatest of intellects occasionally fall into this irrational trap. For instance, Albert Einstein (1879-1955), one of the greatest intellects of the 20th or any other century, challenged the age-old common-sense assumption that time is invariable-a second, a minute, or an hour is the same for you as it is for me. But it isn't. For ordinary purposes we may assume time is invariable. However, challenging this assumption led Einstein to develop the Theory of Relativity and unlocked the awesome potential of nuclear energy.

Even though he had the flexibility of mind to challenge and disprove this most basic of all assumptions, to the end of his life Einstein was unable to accept challenges to certain other basic assumptions posed 
by the then-emerging science of quantum physics. He simply refused to believe the universe could possibly operate the way quantum physics says it does.

However, he was wrong. Quantum physics is now well established and its assumptions, however bizarre, for the most part have been experimentally demonstrated.

Alas, we are all human. For better or worse, we are all subject to the failing of wanting to hang on to certain beliefs despite overwhelming evidence to the contrary. In this respect, we and Albert Einstein have much in common.

\begin{abstract}
About the Author
Philip Yaffe was born in Boston, Massachusetts, in 1942 and grew up in Los Angeles, where he graduated from the University of California with a degree in mathematics and physics. In his senior year, he was also editor-in-chief of the Daily Bruin, UCLA's daily student newspaper. He has more than 40 years of experience in journalism and international marketing communication. At various points in his career, he has been a teacher of journalism, a reporter/feature writer with The Wall Street Journal, an account executive with a major international press relations agency, European marketing communication director with two major international companies, and a founding partner of a specialized marketing communication agency in Brussels, Belgium, where he has lived since 1974. He is author of 14 books, which can be found easily in Amazon Kindle.
\end{abstract}

\title{
References
}

[1] Asimov, I. "Reason." In I, Robot. First edition. Gnome Press, New York, 1950.

[2] Wells, H. G. "The Country of the Blind." In The Country of the Blind and Other Stories. Thomas Nelson and Sons, Edinburgh, 1911.

DOI: $10.1145 / 2886415$ 